\title{
Representations of Medical Risks and Their Connection to Different Personal Characteristics of Doctors and Medical Students
}

\author{
Tatiana V. Kornilova ${ }^{a}$, Elizaveta M. Pavlova ${ }^{a^{*}}$, Nataliya V. Bogacheva ${ }^{\mathrm{b}}$, \\ Igor I. Kamenev ${ }^{a}$, Yulia V. Krasavtseva ${ }^{a}$ \\ a Lomonosov Moscow State University, Moscow, Russia \\ ${ }^{\mathrm{b}}$ I.M. Sechenov First Moscow State Medical University (Sechenov University), Moscow, Russia \\ * Corresponding author. E-mail: pavlova.lisa@gmail.com
}

Background. There is no generally accepted psychological understanding of how a doctor's representation of risk and uncertainty affects professional medical decision-making. The concept of a Unified Intellectual and Personal Potential can serve as a framework to explain its multiple and multilevel regulation. Our objective was to research the connections between medics' perceptions of risk and related personal factors.

Design. Medical doctors were compared to different control groups to identify their personal and motivational characteristics in three studies. Study 1 assessed the motivational profile of doctors (using Edwards Personal Preference Schedule) in connection with their risk-readiness and rationality (measured by the Personal Factors of Decision-making questionnaire, also known as LFR) in a sample of 33 doctors, as compared to 35 paramedics and 33 detectives. Study 2 compared 125 medical students and 182 non-medical students to 65 doctors as to the levels of their risk perception (measured by Implicit Theories of Risk questionnaire, the LFR, and their direct self-esteem of riskiness ${ }^{\alpha}$ ), tolerance for uncertainty (measured by Budner's questionnaire), and rating on the Big-Five personality traits (TIPI). Study 3 presented two new methods of risk perception assessment and investigated the connection between personality traits, risk reduction strategies, and cognitive representations of risk in 66 doctors, as compared to 44 realtors.

Results. Study 1 found differences between the doctors', paramedics', and investigators' motivational profiles. The doctors' motivations were not associated with conscious self-regulation. In Study 2, risk-readiness was positively related to tolerance for uncertainty (TU) and the self-esteem of riskiness. The latter was significantly lower in doctors compared to the student groups and had different relationships with personality variables. In Study 3, doctors differed from realtors not only in their traits (i.e., being less willing to take risks), but also in their choices and greater integration of their risk representations.

Conclusions. The three studies demonstrated the multilevel processes behind the willingness to take risks and risk acceptance, as well as the relationship between the multilevel personality traits and doctors' assessments of medical risks and their preferences in risky decision-making.
Keywords: decision-making (DM); risk representation; risk-readiness; implicit theories (IT); Implicit Theories of Risk (ITR); self-esteem of riskiness; tolerance for uncertainty (TU); Big Five 


\section{Introduction}

In various professions, decision-making (DM) under conditions of uncertainty involves not only subjective risk for the decision-maker him/herself, but also might be a source of risk and danger for someone else. Medicine is an example of such a profession (Heller, Saltzstein, \& Caspe, 2017). This profession is essential in one's life, but there's no generally accepted psychological understanding of how a doctor's representation of risk and uncertainty affects his/her professional decision-making.

The medical professional has to utilize decision-making and basic knowledge in his/her analysis of any specific individual case. Risk perception and implicit theories of risk (ITR) constitute cognitive components of DM, and they interact with different strategies for using professional knowledge (Kahneman, Slovic, \& Tversky, 1982). Personal characteristics are also part of DM regulation, as has been shown in the research on the framing effect (Kahneman, 2011; Kornilova, Kerimova, 2018) and on the connection between DM and personal and motivational characteristics of medical professionals (e.g., Kamenev, Kornilova, \& Razvalyaeva, 2018).

Despite the active development of various risk assessment scales in medical practice, designed to simplify and increase the objectivity of medical DM (e.g., Diadichkina, Radetckaia, 2016; Suriadi, Sanada, \& Sugama, 2008), practicing doctors tend to rely more on their clinical experience. At the same time, "mechanized" DM (that based on statistics, risk scales, and other algorithms) shows an advantage in comparison with "clinical" forms of assessment (when one bases their decisions on experience and knowledge without relying on third-party assessment tools). As shown in the literature, "mechanized" decisions are $10 \%$ more accurate than traditional (subjective) risk assessments (Grove, Zald, Lebow, Snitz, \& Nelson, 2000). At the same time, medics do not always base their decisions on rational grounds (Perneger \& Agoritsas, 2011). As the literature shows, doctors tend to test hypotheses during diagnosis in only $39 \%$ of their cases, but in general, tend to search for additional information using inductive methods (Donner-Banzhoff et al., 2017).

One of the principal sources of risk in medical DM is the prognostic aspect of any DM. This aspect is inseparably linked to uncertainty, not only in terms of the results and the probabilistic nature of a patient's symptomatology, but also in terms of the general prognostic character of a professional's world image. This image necessarily includes a dynamic attitude towards uncertainty and risk (Kornilova, 1994; Smirnov, Chumakova, \& Kornilova, 2016).

Perception of risk can function on different levels, ranging from reflections on risk conditions and factors, up to the deeper level of implicit theories (IT). The latter can be part of the existential level of consciousness as defined by V. Zinchenko (2006). They consist of social representations as well as professional systems of knowledge, strategies, and tacit assumptions (Gigerenzer, 2008; Sternberg et al., 2000).

The concept of risk representation implies a cognitive representation of a situation or a task, its outcomes, and possible alternatives. D. Kahneman's and A. Tver-

The "self-esteem of riskiness" refers to an individual's self-esteem in light of their willingness to take risks. This formulation will be used throughout this article, as to constantly elaborate its meaning would be too unwieldy. 
sky's work has shown the role of cognitive representations of uncertain conditions in judgment, and how heuristics condition the situation image (Kahneman, 2011). At the same time, they didn't look into the actual genesis of DM, or its interaction with cognitive, stylistic, and personal variables. In the medical profession, the connection between the perception of medical risks and non-specific ones is also essential.

However, risk perception and personal risk-readiness connect with the personal and cognitive sphere of a person to varying degrees. Normative models of DM under conditions of uncertainty and risk suggest that a person seeks to maximize utility as a result of their DM, but research shows deviations from the "optimal" strategies (Gigerenzer, 2015; Kozeletskii, 1979). The particular characteristics of risk-readiness differ from both impulsivity and sensation seeking (see Lauriola \& Weller, 2018). At the same time, risk readiness, tolerance for uncertainty (TU), and intuition form the latent variable of Acceptance of Uncertainty and Risk (Kornilova, Chumakova, Kornilov, \& Novikova, 2010), which, in turn, links to intelligence through the integrative Self-concept (Novikova \& Kornilova, 2013).

We must distinguish risk readiness as a personal characteristic from implicit theories of risk (ITRs). Implicit theories (ITs) manifest themselves in DM, but are not necessarily recognized by a person. Different aspects of ITRs are actualized in different situations, and that might explain lower correlations between personal factors, self-reports, and real behavior in various professional and everyday situations (Figner \& Weber, 2011).

We assume that cognitive representations of risk are components of the image of the situation; they can act on both the level of ITs and the conscious level of risk-readiness in the assessment of the consequences of a decision. At the same time, they indicate how a hypothesis opens up the situation under the influence of a person's world image (Leontiev, 2003; Smirnov, 2003), an image that varies for representatives of different specialties (it includes both professional knowledge and professional values). DM by a professional is based on his/her world image and an attitude towards uncertainty and risk. It contributes to the specific choice in a given practical situation.

Personal characteristics that contribute to and inhibit risk acceptance have been studied previously (Kornilova, 2016), but the role of the direct self-assessment of one's willingness to take risks has just begun to be considered (Krasavtseva, 2018). At the same time, Acceptance of Risk and Uncertainty can be understood as "trying on" alternatives to a potential decision (Kornilova, 2003), and the individual's selfesteem of riskiness plays an essential role in this process. Studies of DM have shown that people tend to take higher risks for themselves, in contrast to their advice to others (Kamenev et al., 2018).

According to the concept of a person's Unified Intellectual and Personal Potential, an individual's regulation of DM and activity under uncertainty is multiple and multi-level. This notion allows us to study the interaction between the cognitive and personal (and situational and dispositional) aspects of risk representations and medical decision-making. At the same time, such a study can take into account not only cognitive representations of risk in everyday situations, or subjective cognitive representations of a medic's willingness to take risks, but also their interaction, and their connection to the medical risk perception. 
The goal of this paper was to study the connections between a medic's risk perception (from ITRs to the direct self-esteem of riskiness) and the different levels of their personal traits; we used different personal characteristics, ranging from a deep motivation toward the self-esteem of riskiness and stable personal features (such as the Big-Five personality traits), to ones that reflect a person's attitude towards uncertainty. We did not set as a separate goal the investigation of the role of a doctor's ethics in their decision-making process. However, we can assume that ethical principles and following the Hippocratic oath are one of the factors determining the results of this study. In particular, awareness and understanding of the moral aspects of medical decisions are fundamentally different between doctors and medical students (along with other elements of professionalization). Perhaps that is why the idea of risk as something harmful or undesirable (in comparison with a hedonistic interpretation) manifests itself in many aspects of our research.

We believe that the study of risk-readiness and motivational tendencies (diagnosed with Edwards Personal Preference Schedule, Kornilova, 1997a, b) would benefit from the analysis of personal characteristics of professional medics. We have previously outlined the specifics of medics' motivational profiles (Kamenev et al., 2018), but didn't compare them with those of emergency doctors and nonmedical professions. This paper expands our research in this direction. The multilevel structure of an individual's dynamic regulative systems assumes there is a deep level of motivational hierarchies; their relationships with risk-readiness can help establish how closely different kinds of motivation lead toward risk acceptance processes.

\section{Study 1. The Connection between Personal Aspects of Self-Regulation (Risk-Readiness and Rationality)}

\section{Study 1. Overview}

The goal of this study was to compare the personal and motivational profiles of three groups of participants: doctors, paramedics, and detectives of the Investigative Committee of Russia.

We dedicated some of our previous work to the problem of risk perception and risk reduction during DM in doctors (see Bogacheva, Kornilova, \& Krasavtseva, 2017; Kornilova et al., 2010; Pavlova, Kornilova, Krasavtseva, \& Bogacheva, 2019). A. Sakharova compared the prognostic effectiveness of paramedics and doctors; she showed that general anticipation, personality-situational prognostic competence, and the DM in the process of self-control are significantly higher among emergency doctors (Sakharova, 2012).

In our previous research on the connection between kinds of motivation and DM in verbal tasks, a group of paramedics made up about a third of the sample (13 people out of 33, Kamenev et al., 2018). The differences between the doctors and the paramedics in DM were shown to be insignificant. At the same time, in that study, deep motivation was related to the acceptance of risk, and the style of selfregulation was connected to decision confidence but not its orientation.

However, we did not compare the motivational profiles of the doctors and the paramedics. We decided to include more doctors of different specialties in our research to study this problem further. We believe that the differences in work condi- 
tions (a scheduled appointment versus an ambulance) can't be more decisive than the professionalization factor (doctors have more intensive training than paramedics). Therefore, we studied the specifics of personal self-regulation and the deep motivation of the participants as determined by the whole situation, including the unity of the intellectual and personal components of professionalization.

We chose detectives as a control group for this study. There is no current information about detectives' motivational profiles (their latest professiograms were created in 1925 and 1967 - Shadrikov, 1994). However, like doctors, their activity involves following certain norms, detailed intellectual strategies, multi-stage decisions, and taking responsibility for others.

\section{Study 1. Method}

\section{Participants}

The sample consisted of 101 people:

- 33 doctors (13 men, 20 women); ages ranged from 26 to 68 years $(M=45.79$, $\mathrm{SD}=12.58)$;

- 35 paramedics (5 men, 30 women); ages ranged from 25 to 63 years old $(\mathrm{M}=44.11, \mathrm{SD}=8.47)$; and

- 33 detectives (15 men, 18 women); ages ranged from 26 to 56 years old $(\mathrm{M}=39.09, \mathrm{SD}=7.78)$.

The detectives were selected from a larger group of 90 in order to obtain a group equivalent to the medical workers in terms of gender and age. The comparison between doctors and paramedics allows us to take into account the professionalization factor, and with detectives, the factor of the profession itself. At the same time, all of the participants are representatives of the so-called "person-to-person" kind of profession.

The participation in all three studies was anonymous, and all participants signed informed consent.

Work experience was normally distributed (according to Pearson's chi-square crosstab test), but age was not: the doctors turned out to be older than the other groups $(\mathrm{F}=4.173, \mathrm{df}=2.98, \mathrm{p}=.018)$.

\section{Procedure}

\section{Questionnaires}

1. Edwards Personal Preference Schedule (Kornilova, 1997a). This measure evaluates "motivational tendencies" that correspond to G. Murray's types of motivation. The questionnaire has an ipsative format. Motivation tendencies in this questionnaire are shown by the general directions of the person's preferred methods of action and interaction with the social environment. The test has eight scales: achievement; order; autonomy; self-knowledge; dominance; abasement; endurance; and aggression.

2. Personal Factors in Decision-making Questionnaire aka LFR (Kornilova et al., 2010). This was used to measure risk readiness (an ability to make decisions under risk) and rationality (readiness to search for additional information). 


\section{Study 1. Results}

Using the Mann-Whitney U-test, we examined how sex affects motivation and personal factors of DM. According to our results, men tend to be more dominant $(p=.013)$. Other parameters don't show significant differences.

We used Kruskal-Wallis one-way analysis of variance to establish the differences between the variables in the groups (see Table 1).

Table 1

Significant differences in the variables between groups of doctors, detectives, and paramedics (Kruskal-Wallis one-way analysis of variance)

\begin{tabular}{lccccc}
\hline \multicolumn{1}{c}{ Variable } & Groups & $\mathbf{p}$ & $\mathbf{M}_{\text {doctors }}$ & $\mathbf{M}_{\text {paramedics }}$ & $\mathbf{M}_{\text {detectives }}$ \\
\hline Risk-readiness & $\mathrm{P}-D t, D c-D t$ & .030 & 1.24 & 0.91 & 3.33 \\
Rationality & $D c-\mathrm{P}, D c-D t$ & .001 & 6.06 & 8.17 & 7.91 \\
Achievement & $D c-\mathrm{P}, \mathrm{P}-D t$ & .006 & 7.85 & 6.51 & 7.82 \\
Order & $D c-\mathrm{P}, \mathrm{P}-D t$ & .023 & 6.94 & 8.4 & 7.09 \\
Dominance & $D c-\mathrm{P}, \mathrm{P}-D t$ & .001 & 7.88 & 5.54 & 8.97 \\
Abasement & $D c-\mathrm{P}, \mathrm{P}-D t, D c-D t$ & .001 & 5.94 & 8.74 & 4.18 \\
Aggression & $\mathrm{P}-D t, D c-D t$ & .001 & 4.94 & 5.71 & 3.91 \\
\hline
\end{tabular}

Note. $D c=$ doctors, $P=$ paramedics, $D t=$ detectives.

Risk-readiness in the detectives is higher in comparison with other groups, and rationality is lower in the doctors.

The motivation for achievement and dominance is significantly lower among paramedics; at the same time, they have significantly higher aggression, abasement, and love for order. Doctors and detectives have higher dominance and achievement; at the same time, they have lower abasement and aggression.

Correlation analysis shows that motivation is not connected to self-regulatory properties in doctors, and risk-readiness tends to be linked to aggression $(\mathrm{p}=.078)$. Among paramedics, risk-readiness positively correlates with autonomy $(\mathrm{p}=.031)$ and dominance $(\mathrm{p}=.01)$ and negatively correlates with abasement $(\mathrm{p}=.05)$. Rationality in this group positively correlates with order $(\mathrm{p}=.027)$ and negatively with aggression $(\mathrm{p}=.012)$. Finally, detectives' motivational scales do not correlate with risk-readiness, but rationality was positively associated with $\operatorname{order}(\mathrm{p}=.01)$ and negatively with self-knowledge $(\mathrm{p}=.016)$.

\section{Study 1. Discussion}

Correlation analysis established that the components of motivation and personal self-regulation of DM (namely risk-readiness and rationality) are not integrated among doctors, as compared to paramedics, who also have a stronger desire for order, as well as exhibiting aggression and abasement. This connection is quite convincing: people with a stronger desire for order are more rational, and those who are abased (willing to accept blame) are less risk-ready. Thus, there are reasons to 
associate paramedics' lower level of basic knowledge and their activity with a more pronounced motivational regulation.

The group of detectives appears intermediate: they don't demonstrate the connection between motivation and risk-readiness that the doctors do, and their rationality correlates with the desire for order like the paramedics. In general, they have less correlation between variables as compared to paramedics.

Doctors and detectives are involved in a more intellectual activity than paramedics. Quasi-experimental comparison results (for the student sample) show that people with lower intelligence tend to manifest more personal-motivational regulation of their cognitive activity (Chumakova, 2010; Shadrikov, 2017). In our study, we found that doctors demonstrated lower rationality, which may be due to their being more critical in the self-assessments the questionnaire is based on. In general, the results of Study 1 allow us to consider the differences between groups in the context of the differences in their professionalization and intellectual activity. These may be the reason there are no significant connections with deeper motivational levels among the doctors and as compared to the paramedics.

\section{Study 1. Conclusion}

The following two studies are dedicated to analyzing actual DM situations and risk perception among doctors, and include analysis of their characteristics on different levels (from personal traits to self-esteem and ITRs).

\section{Study 2. Risk Representation Levels of Doctors and Students}

\section{Study 2. Overview}

Personal risk-readiness includes perception of risk, although risk-readiness can't be reduced to it. In Study 2, we identify relationships between the self-esteem of riskiness, ITRs (Implicit Theories of Risk as unrecognized implicit representations of risk perception), and risk-readiness and rationality (as personal properties of self-regulation).

We believe that the acceptance of risk is based on personal experience that crystallizes in the form of 1) implicit perceptions of situations and sources of risk (Slovic, 1984, 2000); and 2) the person's own readiness for action and DM under conditions of uncertainty or danger (Kornilova, 2016).

ITRs include not only common knowledge, but also different forms of tacit assumptions formed in professional activity (Sternberg, 2000). They are related to critical thinking and personal traits of self-regulation. We consider ITs less as perceived parts of risk perception, than as reflecting the self-esteem of riskiness. Selfesteem represents an assessment of one's capabilities for making choices in a risk situation.

In Study 2, we identified the features of direct self-esteem of riskiness, ITs, and personal risk-readiness by comparing 1) medical practitioners and medical students, and 2) students at medical and non-medical universities.

We tested the hypothesis about the role the stage of professionalization plays in determining the interconnections between the processes behind the latent variable Accepting Uncertainty and Risk. 


\section{Study 2. Methods}

\section{Participants}

372 people participated in the study:

- 65 doctors (28 men and 37 women); ages ranged from 24 to 73 years old $(\mathrm{M}=41, \mathrm{SD}=12.5)$; with professional experience from 1 to 50 years $(\mathrm{M}=15.7, \mathrm{SD}=11.9)$;

- 125 students from First Moscow State Medical University, Department of Pediatrics and Department of Medicine (36 men and 89 women); ages ranged from 17 to 29 years old $(\mathrm{M}=19, \mathrm{SD}=1.4)$; and

- 182 students from Lomonosov Moscow State University, Department of Psychology (18 men and 164 women); ages ranged from 18 to 33 years old $(\mathrm{M}=19.8, \mathrm{SD}=1.3)$.

\section{Procedure}

\section{Questionnaires}

1. Implicit theories of risk questionnaire (ITR, Ordinova, 2013). This considers ITRs as stable individual perceptions of risk and risk situations, and has seven scales: 1) impossibility of prognosis/calculation; 2) risk as a conscious choice (conscious violation of standards, willingness to act without regard to danger); 3 ) risk as a challenge; 4) risk as a lack of rationality and control over the situation; 5) risk as acquisition of value; 6) risk as a loss or gain; and 7) risk as pleasure (risk as a search for vivid impressions, a source of positive experiences).

2. Budner's questionnaire (Kornilova, Chumakova, 2014). This measures two scales: 1) tolerance for uncertainty (TU, as a personal characteristic that reflects one's readiness act in uncertain situations), and 2) intolerance for uncertainty (ITU, a pursuit of clarity, simplicity).

3. Personal Factors of Decision-making Questionnaire aka LFR (Kornilova, et al., 2010). See description in Study 1.

4. Ten-Item Personality Measure (TIPI, Gosling, 2013). This was adapted for a Russian sample by Kornilova and Chumakova (2016) and used to measure extraversion, agreeableness, conscientiousness, emotional stability, and openness.

5. The self-esteem of riskiness (Kornilova et al., 2010). This was measured using a procedure analogous to the self-esteem of intelligence proposed by Furnham (2001). In this method, participants are asked to assess their level of willingness to take risks based on the normal distribution graph $(M=100, S D=15)$.

\section{Study 2. Results}

The significant differences between the groups are shown in Table 2.

Medical students have higher risk-readiness than psychology students $(\mathrm{p}=.002)$. Doctors show significantly lower risk-readiness in comparison with medical students $(\mathrm{p}=.001)$, but not psychology students, who also have lower rationality $(\mathrm{p}=.031)$. At the same time, the groups do not differ in their TU-ITU.

Next, doctors show a significantly higher level of conscientiousness in comparison with both student groups $(\mathrm{p}=.026, \mathrm{p}=.001)$. At the same time, they are more emotionally stable than the psychology students $(\mathrm{p}=.008)$. 
Table 2

Significant differences in ITR, LFR, Big-Five factors, and self-esteem of riskiness between groups of doctors, medical students, and psychology students (Kruskal-Wallis one-way analysis of variance).

\begin{tabular}{|c|c|c|c|c|c|c|}
\hline & & $\mathbf{H}$ & p & $\begin{array}{l}M_{\text {medics }} \\
\text { (SD) }\end{array}$ & $\begin{array}{l}M_{\text {medical students }} \\
\text { (SD) }\end{array}$ & $\begin{array}{c}M_{\text {psychology students }} \\
\text { (SD) }\end{array}$ \\
\hline \multirow{3}{*}{ 唲 } & Risk as a challenge & 9.125 & .010 & $13.3(2.7)$ & $14.6(2.9)$ & $14.2(2.9)$ \\
\hline & Lack of rationality & 13.976 & .001 & $22.3(3.8)$ & $20.9(3.5)$ & $20.7(4.1)$ \\
\hline & Pleasure & 10.622 & .005 & $16.5(3.7)$ & $18.7(4.5)$ & $18.1(3.8)$ \\
\hline \multirow{2}{*}{ 㐍 } & Risk-readiness & 19.866 & .001 & $0.5(3.2)$ & $2.4(4.1)^{\star}$ & $.5(4.6)^{\star}$ \\
\hline & Rationality & 5.991 & .050 & $5(3)$ & $4.1(2.8)$ & $3.8(3.8)$ \\
\hline \multirow{2}{*}{$\overrightarrow{\stackrel{G}{G}}$} & Conscientiousness & 17.351 & .001 & $11.2(2.3)$ & $10.1(2.5)$ & $9.4(3.2)$ \\
\hline & Emotional stability & 9.024 & .011 & $8.7(2.8)$ & $7.8(2.7)$ & $7.4(2.8)$ \\
\hline \multicolumn{2}{|c|}{ Self-esteem of riskiness } & 8.179 & .017 & $90.2(20.4)$ & $99.8(22.9)$ & $98.6(21.6)$ \\
\hline
\end{tabular}

Note. Bold=significant differences found in pairwise comparison $(p<.05) ;{ }^{*}=$ significant differences between student groups; only scales with significant differences $(p<.05)$ are shown.

The participants from the different groups also show different ITRs. For doctors, it's more common to see risk as a lack of rationality $(\mathrm{p}=.009$ with medical students, $\mathrm{p}=.001$ with psychology students), and less as a challenge (only in comparison with medical students, $\mathrm{p}=.008)$. At the same time, they are less susceptible to hedonistic risk than the other two groups ( $\mathrm{p}=.004$ with medical students, $\mathrm{p}=.037$ with psychology students). Finally, both student groups assess their willingness to take risks higher than the doctors do ( $\mathrm{p}=.027$ with medical students, $\mathrm{p}=.028$ with psychology students).

We conducted a correlation analysis to clarify the specific characteristics of groups (the correlations between variables are shown in Tables 1 and 2 in the Appendix).

All groups demonstrate significant connections between self-esteem of riskiness and risk-readiness. The latter, in turn, is positively connected to extraversion and negatively to rationality and ITR conscious choice. ITU in all groups relates to the ITR lack of rationality. The rest of the correlations are specific to each group.

The connection between the self-esteem of riskiness and ITR acquisition of value was found only among the doctors. At the same time, the self-esteem of the students in both groups positively correlates to ITRs conscious choice, extraversion, and openness, and negatively to ITU. Psychology students' self-esteem of riskiness also links to rationality and the ITR impossibility of prognosis.

In the medical students, $T U$ correlates to ITR pleasure, but among psychology students, it relates to ITR challenge (positively) and ITR acquisition of value (negatively). ITU is connected to ITR acquisition of value (in both student groups), and negatively to conscious choice and hedonistic risk among medical students.

Risk-readiness positively connects to ITR pleasure in medical students. Psychology students demonstrate a different profile: their risk-readiness positively corre- 
lates with risk as a challenge and negatively correlates with ITR acquisition of value. Rationality measured with LFR among doctors and psychology students correlates with the ITR lack of rationality. Psychology students also show a correlation of rationality with ITR conscious choice (negative) and ITR loss or gain (positive). Medical students also demonstrate the link between rationality and risk as a result of an impossibility of prognosis.

Finally, there is a difference in the correlations of personal characteristics between the groups. The rationality of doctors significantly connects to their conscientiousness and emotional stability. Medical students demonstrate the relationship between rationality and ITU (positive) and extraversion (negative). Their risk-readiness also relates to openness. In psychology students, rationality correlates with conscientiousness (same with doctors) and negatively with openness; risk-readiness links to all factors of the Big-Five except for conscientiousness; TU correlates with risk-readiness.

\section{Study 2. Discussion}

We established the existence of differences in the self-esteem of riskiness between professionals and students (the student groups have no difference between them). The lower self-esteem of riskiness of the doctors may be connected to their higher degree of caution, and the fact that the doctors' group is older in general.

The self-esteem of riskiness demonstrates the diverse structure of connections among the different groups. A doctor's self-esteem relates only to personal riskreadiness, but among students of both professions, it links to intolerance for uncertainty, extraversion, and openness. We can assume that criteria for self-assessment may vary. The lack of connections of self-esteem with other variables may indicate that participants base their self-esteem on their self-concept, and also have a more differentiated interpretation of willingness to take risks as a trait.

All groups show a correlation between self-esteem of riskiness and the IT conscious choice. This relationship suggests that this IT corresponds with the general criterion of risk: doctors and students see riskiness as an intentional violation of norms. Doctors differentiate themselves from the other groups by their link between self-esteem of riskiness and ITR acquisition of value, which represent risk as a "trial of fate" and the source of rewards. This representation points to the role of risk-taking in fateful decisions, an essential aspect of medical professional activity, which has to deal with issues of life or death.

We establish the differences in risk-readiness (medical students are more riskready than two other groups), rationality (doctors are more rational in comparison with psychology students), conscientiousness (doctors have higher conscientiousness), and emotional stability (doctors are more stable than psychology students). These results reflect the path of professionalization that medics take; they have to overcome their risk-readiness. Thereby, we can assume that a medic's professionalization implies the additional differentiation of personality traits that allow them to control their actions better. This control is vital because of the high cost of risk in the medical profession. This assumption also explains the shift from the positive interpretations of risk towards more "serious" ones (like the lack of rationality or the value aspect of risk). 
We haven't found any difference between doctors and students in their TU$I T U$; this confirms the idea that high $T U$ is a selection (and self-selection) criterion for the medical profession (Geller, 2013).

Doctors have higher rationality and lower risk-readiness in comparison with students. This shows that we need to differentiate between cognitive assessment processes and risk acceptance in professionalization. Study 1 showed that doctors have higher rationality in comparison with other professional groups. The results of Study 2 indicate that medical students haven't mastered the ability to maximize their search for information in DM. At the same time, the rationality of doctors has a tight association with the personal factors of conscientiousness and emotional stability, and no connection to TU-ITU, unlike the student groups.

\section{Study 2. Conclusion}

A doctor's self-esteem of riskiness associates only with risk-readiness and the ITR acquisition of value, but student groups demonstrate various connections between different personality traits and ITs. Thus, risk self-awareness in the student group tends to be less differentiated compared to that of the professionals. Various ITRs also correlate with each other in the student groups. Altogether this can be evidence of the greater integration of the multilevel processes associated with cognitive-personal regulation of DM under conditions of risk and uncertainty in this group.

ITs are the result of learning experiences. Therefore, a doctor's development follows the path of differentiation, specification, and the separation of implicit perceptions of risk from each other. At the same time, the ITR pleasure is reduced during professionalization and loses its connection with different traits. This suggests a transition from a positive interpretation of risk, to one seeing it as a threat, over the course of doctors' professional development.

\section{Study 3. Relationships Between the Personal Characteristics of Doctors and Realtors and their Medical Risk Assessments}

\section{Study 3. Overview}

On the one hand, risk perception and readiness to take on tasks have a multi-level structure. On the other hand, we have to take into account the base knowledge that doctors use when making a decision. This requires us to use some special measurements of medical risk: the Medical Risk Scale (MRS) and the Cognitive Representations of Risk (CRR) questionnaire.

The CRR Questionnaire reflects different aspects of professional and non-specific risks, and the MRS consists of verbal tasks (vignettes) based on medical practice. Both specify specific risk sources and alternative ways of reducing risk (the control group makes its decisions as if they were medics).

Study 3 has two goals. The first is to establish the links between the conscious aspects of risk perception (rated in the CRR) and verbal choice preferences (measured by the MRS); and the second is to study the relationships between a direct risk assessment (shown in CRR), and the attitude towards it in verbal tasks, as shown in the MRS and ITRs. 
In this study, we tested the following hypothesis: cognitive representations of risk correlate with professional verbal choice preferences; ITRs are also included in the regulation of choice (and correlate with MRS).

Realtors were chosen to be a control group, because they also have to take risks involving other people, although those risks concern their financial state. We have discussed the psychological profile of realtors, their motivation, and personal selfregulation in our previous work (Kulagina \& Kornilova, 2005).

\section{Study 3. Methods}

\section{Participants}

110 people participated in Study 3:

- 66 doctors (29 men and 37 women); ages ranged from 24 to 73 years old $(\mathrm{M}=41.0, \mathrm{SD}=12.5)$; and

- 44 realtors (8 men and 36 women); ages ranged from 21 to 71 years old $(\mathrm{M}=45.6, \mathrm{SD}=9.3)$.

\section{Procedure}

\section{Questionnaires}

1. The Medical Risk Scale (MRS) was developed to assess medical risk representation and methods for risk reduction. This questionnaire includes 10 verbal tasks (vignettes) created based on interviews with doctors; these vignettes describe different risk situations from within medical practice. Each case has to do with one of the following sources of risk: lack of skills; lack of knowledge; the patient's state of health; the patient's psychology; the lack of equipment; the personality and condition of the doctor; actions of the management; actions of colleagues; imperfections of medicine as a science; the risk of incorrect assessment of the situation; and timing. Participants assessed the riskiness of each situation using a 5-point Likert scale and then chose one of the ways to reduce this risk.

2. The Cognitive Representations of Risk questionnaire (CRR, see Appendix 5) is a list of 21 risks (identified in the qualitative analysis of interviews with doctors). The list consists of both professional medical risks (i.e., "lose a patient") and non-specific risks (i.e., "ruin relations with superiors"). Participants are asked to assess risks by seven aspects: 1 ) riskiness of the situation; 2 ) its predictability; 3) the likelihood of its occurrence in general and 4) in their practice; 5) the intensity of their experience (emotion); and the probability of a 6) positive and 7) negative outcome.

We also used the Personal Factors of Decision-Making Questionnaire (LFR), the S. Budner Questionnaire, ITR, TIPI, and the Self-esteem of Riskiness (see descriptions in Study 1 and 2).

\section{Study 3. Results}

We established the discrepancies between the groups (see Table 3). The factors of the Big-Five and the CRR scales showed no significant difference between them. 
Table 3

Significant differences in Personal Factors of Decision-Making, ITR, and MSR between groups of doctors and realtors (Student's T-test)

\begin{tabular}{lcccc}
\hline & $\mathrm{t}$ & $\mathrm{p}$ & $\mathrm{M}_{\text {doctors }}$ & $\mathrm{M}_{\text {realtors }}$ \\
\hline Risk-readiness (LFR) & -4.653 & .001 & -.54 & 2.51 \\
\hline Lack of rationality & 2.655 & .009 & 22.86 & 20.60 \\
Acquisition of value & 3.468 & .001 & 18.91 & 16.57 \\
Gain or loss & 1.881 & .063 & 25.91 & 23.93 \\
$\quad$ Average risk & 3.673 & .000 & 2.84 & 2.34 \\
Average riskiness when finding information & -2.996 & .004 & 2.96 & 3.44 \\
\multirow{2}{*}{ Average riskiness when delegating decision } & -3.414 & .001 & 2.33 & 3.16 \\
Average riskiness when following intuition & -2.615 & .011 & 2.41 & 3.06 \\
\hline
\end{tabular}

Doctors and realtors do not differ in their TU-ITU and rationality, but doctors have lower risk-readiness in comparison with realtors (similar results obtained in Study 1 and 2).

The two groups demonstrate differences in ITR: doctors see risk more as a lack of rationality, a way to acquire value, and gain or loss.

At the same time, doctors tend to perceive the vignettes of MRS as riskier, and they also prefer to follow intuition and delegate decisions in more dangerous situations, and to find additional information in safer cases.

Correlation analysis (see Table 3 in Appendix) shows the relationship between variables. Doctors and realtors both show the link between TU and risk-readiness ( $\mathrm{p}=.020$ and .014 respectively), but the realtors' $T U$ also relates to risk-readiness $(\mathrm{p}=.021)$. The ITU of doctors negatively links to risk-readiness and positively to rationality $(\mathrm{p}=.027)$. Therefore, more rational and less risk-ready doctors tend to seek clarity. At the same time, the self-esteem of riskiness in both groups correlates with risk-readiness $(\mathrm{p}=.003, .005)$, but only in the case of doctors does it link to ITU ( $\mathrm{p}=.028)$; for realtors it negatively connects to rationality $(\mathrm{p}=.007)$. Medics also show a positive connection between risk-readiness and extraversion $(\mathrm{p}=.010)$.

TU-ITU does not correlate with the Big-Five, but conscientiousness positively relates to rationality in groups of doctors and realtors $(\mathrm{p}=.001$ and .013 respectively). Emotional stability links to rationality in doctors $(\mathrm{p}=.003)$, and negatively to risk-readiness in realtors $(\mathrm{p}=.010)$.

Table 4 in the Appendix shows correlations between the different scales of cognitive representations of risk. According to our results, doctors are characterized as having more integrated risk assessments when choosing to find information, postpone decisions, delegate decisions, follow standards, and use intuition. The control group does not show correlations between these parameters.

A similar pattern is shown for the Cognitive Representations of Risk questionnaire findings. Doctors' risk characteristics are more related to each other than those of the realtors.

Finally, the ITRs show more correlations in doctors as well. 


\section{Study 3. Discussion}

The results allow us to support the hypothesis that ITRs and Cognitive Representations both play a role in regulating DM.

Doctors not only show less risk-readiness, but also exhibit a diverse representation of risk in the form of ITRs. They see risk primarily as a prerequisite for loss or gain, as a lack of rationality, and a way to achieve higher value (the latter is characteristic of doctors with a high self-assessment of riskiness). Realtors with high self-esteem of riskiness are the ones who think a negative outcome is unlikely, and have ITR conscious choice.

Correlation analysis showed that the doctors who don't attempt to clarify the situation also consider themselves willing to take risks. The willingness of realtors to take risks relates to their lesser rationality and emotional stability. Doctors also demonstrate the relationship between rationality and such factors of the Big-Five as conscientiousness and emotional stability.

The results we obtained suggest that doctors have more integrated representations of risk. At the same time, they also demonstrate more links between different cognitive representations of risk, in particular in their assessment of predictability and probability. This shows that doctors tend to distort the probability estimates of medical risks (Kahneman et al., 1982; Operskalski, Barbey, 2016). Cognitive psychologists tend to consider these characteristics of DM as a cognitive distortion, but we showed that they are a part of the doctor's cognitive representation of risk. Earlier, we assumed that a medic's tendency to over-examine patients reflected their pursuit of full orientation in the situation before him/her (Bogacheva et al., 2017).

\section{Study 3. Conclusion}

According to our results, doctors differ from realtors not only in their traits (they are less prone to take risks), but also in their choices and greater integration of CRR.

Personal risk-readiness correlates with the self-esteem of riskiness, and it allows us to consider risk readiness as an integral part of self-concept. The relationships between risk-readiness and ITR as a value, and risk as a conscious choice, allow us to consider ITs as part of the "existential" level of self-awareness.

\section{General Conclusion}

1. In general, the results of our three studies demonstrate the multilevel processes behind the personality traits of willingness to take risks and risk acceptance, as well as the relationship between these multilevel characteristics and doctors' assessments of medical risks and their preferences in risky DM.

2. The study established the differences in the motivational profile of doctors (in comparison with paramedics and investigators). At the same time, the different types of motivation in doctors were shown not to be associated with conscious self-regulation (by risk and rationality scales).

3. Risk readiness positively relates to TU (for medical groups and control groups) and with the self-esteem of riskiness. 
4. Doctors' self-esteem of riskiness is significantly lower than that among medical students and psychology students; their self-esteem of riskiness also differs in relationships with other personality variables.

5. The comparison of two new medical risk measurements showed that doctors who underestimate the likelihood of a positive outcome see risk as a challenge; the risk is seen as a loss or gain by those who tend to assess a situation as risky, and assume higher predictability and probability of risks in general.

6. Components of different levels of risk representation (from conscious direct assessments to implicit ideas) relate to the ways a person chooses to reduce risk in verbal tasks; at the same time, the intra-level connections are more integrated than inter-level ones.

\section{Limitations}

Our samples were not balanced by age and gender, due to the real-life ratio of men and women in different medical specialties; the age differences between students and practitioners were evident as well. These factors can limit our capability of reaching broader conclusions and could have obscured some less noticeable results as well. In the future research, it would be interesting to compare representations of risk in medical professionals of different specialties, and include residents as one of the comparison groups, in order to further understand the dynamics of representations of risk and risk-related personality traits through the process of professionalization of medical doctors.

\section{Acknowledgments}

This research was supported by the Russian Foundation for Basic Research (Project No. 17-06-00130a)

\section{References}

Bari, A., Khan, R.A., \& Rathore, A.W. (2016). Medical errors; causes, consequences, emotional response, and resulting behavioral change. Pakistan Journal of Medical Sciences, 32(3), 523-528. https://doi.org/10.12669/pjms.323.9701.

Blumenthal-Barby, J., \& Krieger, H. (2015). Cognitive Biases and Heuristics in Medical Decision Making: A Critical Review Using a Systematic Search Strategy. Medical decision making: an international journal of the Society for Medical Decision Making, 35(4), 539-57. https://doi.org/10.1177/0272989x14547740

Bogacheva, N.V., Kornilova, T.V., \& Krasavtseva, Yu.V. (2017). Svyazi samootsenok, implitsitnykh teorii riska i lichnostnoi gotovnosti k risku u meditsinskikh rabotnikov [Relationships of selfesteem, implicit theories of risk, and personal risk-readiness for health workers]. Vestnik Moskovskogo gosudarstvennogo oblastnogo universiteta. Seriya "Psikhologicheskie nauki" [Bulletin of Moscow State Regional University. "Psychological Sciences" series], 4, 6-19. https://doi. org/10.18384/2310-7235-2017-4-6-19

Budner, S. (1962). Intolerance of ambiguity as a personality variable. Journal of Personality, 30, $29-59$. https://doi.org/10.1111/j.1467-6494.1962.tb02303.x

Chumakova, M.A. (2010). Intellektualno-lichnostnye i kreativnye komponenty reguliatcii resheniia konstruktivnykh zadach [Intellectual-personal and creative components of solving constructive problems regulation]. Voprosy psikhologii [Psychology Issues], 4, 83-93. 
Donner-Banzhof, N., Seidel, J., Sikeler, A.M., Bosner, S., Vogelmeier, M., Westrum, A., .. \& Gigerenzer, G. (2017). The Phenomenology of the Diagnostic Process: A Primary Care-Based Survey. Medical Decision Making, 37(1), 27-34. https://doi.org/10.1177/0272989x16653401

Dyadichkina, O.V., \& Radetskaya, L.E. (2016). Shkala otsenki riska razvitiya spontannykh prezhdevremennykh rodov [Risk assessment scale for spontaneous preterm birth]. Meditsinskie novosti [Medical news], 2, 72-75.

Furnham, A. (2001). Self-estimates of intelligence. Personality and Individual Differences, 31, 13811405. https://doi.org/10.1016/s0191-8869(00)00232-4

Geller, G. (2013). Tolerance for ambiguity: an ethics-based criterion for medical student selection. Academic Medicine, 88(5), 581-584. https://doi.org/10.1097/acm.0b013e31828a4b8e

Gigerenzer, G. (2008). Moral intuition - fast and frugal heuristics? In W. Sinnott-Armstrong (Eds.), Moral Psychology: Vol. 2. The cognitive science of morality: Intuition and diversity (pp. 1-28). Cambridge, MA: MIT Press. https://doi.org/10.7551/mitpress/7573.003.0003

Gigerenzer, G. (2015). Simply rational: Decision making in the real world. N.Y.: Oxford University Press. https://doi.org/10.1093/acprof:oso/9780199390076.001.0001

Grove, W., Zald, D., Lebow, B., Snitz, B., \& Nelson, C. (2000). Clinical Versus Mechanical Prediction: A Meta-Analysis. Psychological Assessment, 12, 19-30. https://doi.org/10.1037//1040-3590.12.1.19

Heller, R.F., Saltzstein, H.D., \& Caspe, V.B. (1992). Heuristics in Medical and Non-Medical Decision-Making. The Quarterly Journal of Experimental Psychology Section A, 44(2), 211-235. https://doi.org/10.1080/02724989243000019

Kahneman, D. (2011). Thinking, Fast and Slow. New York: Farrar, Straus, and Giroux. https://doi.org/10.4324/9781912453207

Kahneman, D., Slovic, P., \& Tversky, A. (1982). Judgment under uncertainty: Heuristics and biases. Cambridge: Cambridge University Press. https://doi.org/10.1017/cbo9780511809477.002

Kamenev, I.I., Kornilova, T.V., \& Razvalyaeva, A.Yu. (2018). Svyazi riska pri prinyatii reshenii s motivatsiei i samoregulyatsiei (na vyborke meditsinskikh rabotnikov) [Relationship of risk, motivation, and self-regulation in decision making (on a sample of medical workers). Voprosy psikhologii [Psychology Issues], 1, 127-137.

Kornilova, T.V. (1994). Risk i myshlenie [Risk and thinking]. Psikhologicheskii zhurnal [Psychological Journal], 15(4), 20-32.

Kornilova, T.V. (1997a). Diagnostika motivatsii i gotovnosti $k$ risku [Diagnostics of motivation and risk-readiness]. M.: Institut psikhologii RAN.

Kornilova, T.V. (1997b). Teoreticheskie konstrukty i psikhologicheskaia realnost $\mathrm{v}$ indeksakh motivatcii oprosnika A. Edvardsa [Theoretical constructs and psychological reality in the A. Edwards questionnaire]. Voprosy psikhologii [Psychology Issues], 1, 63-73.

Kornilova, T.V. (2016). Intellektualno-lichnostnyi potentsial cheloveka $v$ usloviyakh neopredelennosti $i$ riska [Intellectual and personal potential of a person under uncertainty and risk]. SPb.: NestorIstoriya.

Kornilova, T.V., \& Chumakova, M.A. (2014). Shkaly tolerantnosti i intolerantnosti k neopredelennosti v modifikatcii oprosnika S. Badnera [Scales of tolerance and intolerance to uncertainty in the modification of S. Budner's questionnaire]. Eksperimentalnaia psikhologiia [Experimental Psychology], 7(1), 58-66.

Kornilova, T.V., \& Chumakova, M.A. (2016). Aprobatciia kratkogo oprosnika bolshoi piaterki (TIPI, KOBP) [Approbation of a brief questionnaire of the Big Five (TIPI, KOBP)]. Psikhologicheskie issledovaniia [Psychological Research], 9(46), 5. Retrieved from http://psystudy.ru

Kornilova, T.V., \& Kerimova, S.G. (2018). Osobennosti lichnostnykh predposylok priniatiia reshenii (na materiale freiming-effekta) $\mathrm{u}$ vrachei i prepodavatelei [Personal prerequisites for decisionmaking (based on the material of the framing effect) among doctors and teachers]. Psikhologiia. Zhurnal Vysshei Shkoly ekonomiki [Psychology. Journal of the Higher School of Economics], 15(1), 22-38.

Kornilova, T.V., Chumakova, M.A., Kornilov, S.A., \& Novikova, M.A. (2010). Psikhologiia neopredelennosti: edinstvo intellektualno-lichnostnogo potentciala cheloveka [The psychology of uncertainty: the unity of the intellectual and personal potential of a person]. M.: Smysl. 
Kozeletskii, Yu. (1979). Psikhologicheskaya teoriya reshenii [Psychological Decision Theory]. M.: Progress.

Kulagina, E.I., \& Kornilova, T.V. (2005). Motivatciia, ratcionalnost i gotovnost k risku v lichnostnom profile rieltorov [Motivation, rationality and risk-readiness in the personal profile of realtors]. Voprosy psikhologii [Psychology Issues], 2, 105-117.

Lauriola, M., \& Weller, J. (2018). Personality and Risk: Beyond Daredevils - Risk Taking from a Temperament Perspective: Theory, Models, and Applications. In M. Raue, E. Lermer \& B. Streicher (Eds.), Psychological aspects of risk and risk analysis: Theory, models, and applications (pp. 3-36). NY: Springer. https://doi.org/10.1007/978-3-319-92478-6_1

Lievens, F., Coetsier, P., De Fruyt, F., \& Maeseneer, J. (2002). Medical Students' Personality Characteristics and Academic Performance: A Five-Factor Model Perspective. Medical Education, 36, 1050-1056. https://doi.org/10.1046/j.1365-2923.2002.01328.x

McCulloch, P., Kaul, A., Wagstaff, G.F., \& Wheatcroft, J. (2005). Tolerance of Uncertainty, Extroversion, Neuroticism, and Attitudes to Randomized Controlled Trials among Surgeons and Physicians. The British Journal of Surgery, 92, 1293-1297. https://doi.org/10.1002/bjs.4930

Mullola, S., Hakulinen, C., Presseau, J., Ruiz de Porras, D.G., Jokela, M., Hintsa, T., \& Elovainio, M. (2018). Personality Traits and Career Choices among Physicians in Finland: Employment Sector, Clinical Patient Contact, Specialty, and Change of Specialty. BMC Medical Education, 18(52). https://doi.org/10.1186/s12909-018-1155-9

Novikova, M.A., \& Kornilova, T.V. (2013). Self-Assessed Intelligence, Psychometric Intelligence, Personality, and Academic Achievement: Two Structural Models. In M. Gowda, A. Khanderia (Eds.), Educational Achievement: Teaching Strategies, Psychological Factors, and Economic Impact (pp. 197-212). NY: Nova Science Publishers.

Operskalski, J.T., \& Barbey, A.K. (2016). Risk literacy in medical decision-making: How can we better represent the statistical structure of risk? Science, 352(6284), 413-414. https://doi.org/10.1126/science.aaf7966

Ordinova, E.M. (2013). Izuchenie implitcitnykh teorii kak sostavliaiushchikh kognitivnogo riska [The study of implicit theories as components of a cognitive risk]. Psikhologicheskii zhurnal [Psychological journal], 349(1), 74-85.

Pavlova, E.M., \& Bogacheva, N.V. (2018). Urovnevaia organizatciia kognitivnykh reprezentatcii riska $\mathrm{u}$ vrachei i rieltorov [Level organization of cognitive representations of risk in doctors and realtors]. Vestnik Moskovskogo universiteta. Seriia 14. Psikhologiia [Moscow University Bulletin. Series 14. Psychology], 4, 32-53. https://doi.org/10.11621/vsp.2018.04.32

Pavlova, E.M., Kornilova, T.V., Krasavtseva, Yu.V., \& Bogacheva, N.V. (2019). Lichnostnyi profil' i regulyatsiya prinyatiya reshenii litsami meditsinskikh spetsial'nostei: ot studenta do praktikuyushchego vracha [Personal profile and regulation of decision-making in relation to medical specialists: from student to medical practitioner]. Vestnik RGGU. Seriya: Psikhologiya. Pedagogika. Obrazovanie [Bulletin of the Russian State Humanitarian University. Series: Psychology. Pedagogy. Education], 2, 97-115. https://doi.org/10.28995/2073-6398-2019-2-97-115

Perneger, T.V., \& Agoritsas, T. (2011). Doctors' and patients' susceptibility to framing bias: a randomized trial. Journal of General Internal Medicine, 26, 1411-1417. https://doi.org/10.1007/s11606-011-1810-x

Pikkel, D., Pikkel, I.Y.S., Sharabi-Nov, A., \& Pikkel, J. (2016). Are doctors risk-takers? Risk Management and Healthcare Policy, 9, 129-133. https://doi.org/10.2147/rmhp.s96005

Sakharova, A.E. (2012). Vliianie vremennogo faktora na prognosticheskuiu sposobnost lichnosti kak subekta priniatiia reshenii (na primere vrachebnoi deiatelnosti) [The influence of the time factor on the prognostic ability of a person as a subject of decision-making (using an example of medical activity)]. Obrazovanie i samorazvitie [Education and self-development], 2(30), 158-164.

Shadrikov, V.D. (1994). Deiatelnost i sposobnosti [Activities and abilities]. M.: Logos.

Sharma, A., \& Kashyap, N. (2017). The Influence of the Big Five Personality Traits on Burnout in Medical Doctors. International Journal of Psychological Studies, 9(13). https://doi.org/10.5539/ijps.v9n4p13

Slovic, P. (2000). The Perception of Risk. Earthscan publication. London: Business \& Economics. https://doi.org/10.4324/9781315661773 
Smirnov, S.D. (2003). Mir obrazov i obraz mira kak paradigmy psikhologicheskogo myshleniia [The world of images and the image of the world as a paradigm of psychological thinking]. Mir psikhologii [World of Psychology], 4, 18-31.

Smirnov, S.D., Chumakova, M.A., \& Kornilova, T.V. (2016). Obraz mira v dinamicheskom kontrole neopredelennosti [The image of the world in the dynamic control of uncertainty]. Voprosy psikhologii [Psychology Issues], 4, 3-13.

Sternberg, R.J., Forsythe, G.B., Hedlund, J., Horvath, J.A., Wagner, R.K., Williams, W.M., ... Grigorenko, E.L. (2000). Practical intelligence in everyday life. New York, NY: Cambridge University Press.

Suriadi, S., Sanada, H., \& Sugama, J. (2008). Development of a new risk assessment scale for predicting pressure ulcers in an intensive care unit. Nursing in Critical Care, 13, 34-43. https://doi.org/10.1111/j.1478-5153.2007.00250.x

Zinchenko, V.P. (2006). Soznanie kak predmet i delo psikhologii [Consciousness as an object and a matter of psychology]. Metodologiya $i$ istoriya psikhologii [Methodology and the history of psychology], 1, 207-231.

Original manuscript received November 12, 2019

Revised manuscript accepted December 24, 2019

First published online March 15, 2020

To cite this article: Kornilova, T.V., Pavlova, E.M., Bogacheva, N.V., Kamenev, I.I., Krasavtseva, Yu.V. (2020). Representations of Medical Risks and Their Connection to Different Personal Characteristics of Doctors and Medical Students. Psychology in Russia: State of the Art, 13(1), 99-120. DOI: 10.11621/pir.2020.0109 


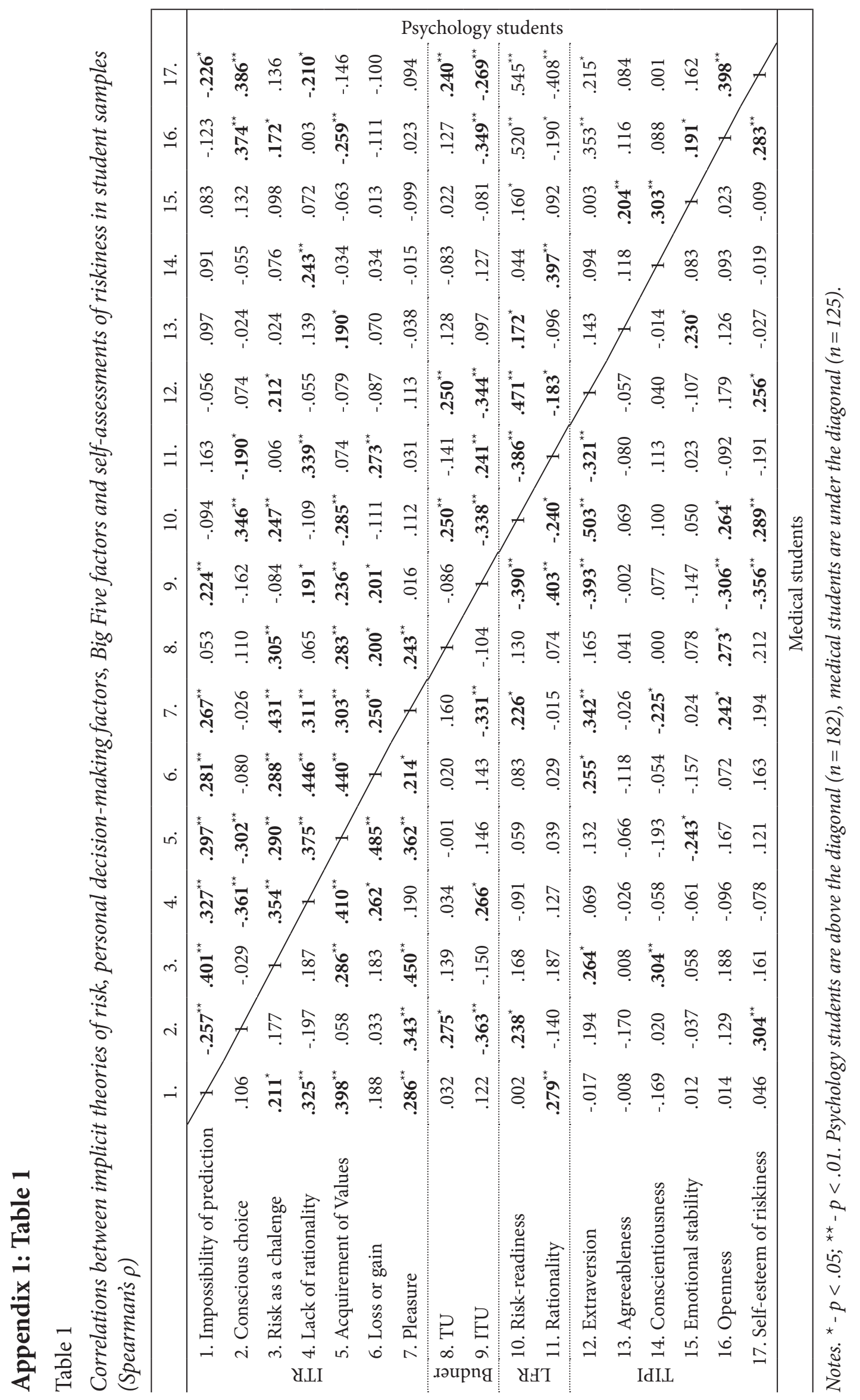




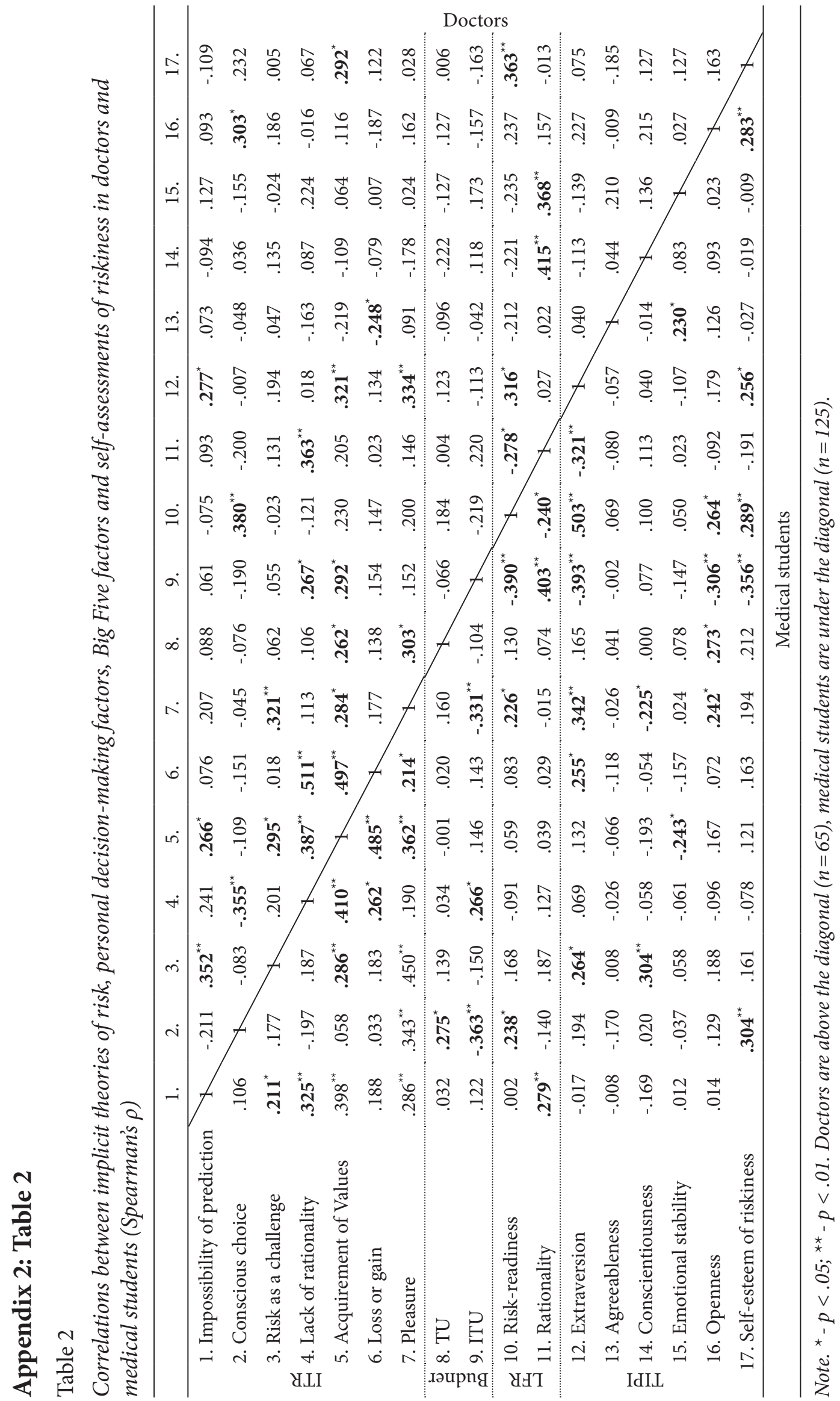




\section{Appendix 3: Table 3}

Table 3

Correlations between TU-ITU, personal decision-making factors, Big Five factors, and selfassessments of riskiness in doctors and realtors (Spearman's $\rho$ )

\begin{tabular}{|c|c|c|c|c|c|c|c|c|c|c|c|}
\hline & 1. & 2. & 3. & 4. & 5. & 6. & 7. & 8. & 9. & 10. & \\
\hline$\grave{\Xi} 1 . \mathrm{TU}$ & & -.060 & $.287^{*}$ & -.052 & .145 & -.116 & -.186 & -.019 & .233 & .159 & \\
\hline صै 2. ITU & .061 & & $-.294^{*}$ & $.274^{*}$ & -.119 & -.014 & .082 & .089 & -.230 & $-.275^{*}$ & \\
\hline 소 3. Risk-readiness & $.453^{*}$ & .052 & . & $-.278^{*}$ & $.316^{*}$ & -.212 & -.221 & -.235 & .237 & $.363^{* *}$ & \\
\hline 4. Rationality & $-.401^{*}$ & -.007 & $-.387^{*}$ & & .027 & .022 & $.415^{* *}$ & $.368^{* *}$ & .157 & -.013 & \\
\hline 5. Extraversion & .349 & .096 & .197 & -.206 & & .040 & -.113 & -.139 & .227 & .075 & $\stackrel{\infty}{0}$ \\
\hline 6. Agreeableness & .194 & .108 & .138 & -.079 & -.089 & & .044 & .210 & -.009 & -.185 & $\stackrel{\circ}{\circ}$ \\
\hline 贰 7. Conscientiousness & -.250 & -.010 & .034 & $.396^{*}$ & -.193 & .160 & & 136 & .215 & .127 & \\
\hline 8. Emotional stability & -.126 & -.093 & $-.329^{*}$ & .187 & -.121 & .043 & .151 & & .027 & .127 & \\
\hline 9. Openness & .176 & -.241 & .008 & .214 & .197 & -.042 & .114 & .003 & & .163 & \\
\hline 10. Self-esteem of riskiness & .045 & -.086 & $.443^{* *}$ & $-.423^{* *}$ & .174 & -.252 & -.261 & $-.352^{*}$ & -.082 & & \\
\hline
\end{tabular}

Note. ${ }^{*} p<.05,{ }^{* *} p<.01$. Doctors are above the diagonal; realtors are under the diagonal.

\section{Appendix 4: Table 4}

Table 4

Correlations of cognitive representations factors (Spearman's $\rho$ )

\begin{tabular}{|c|c|c|c|c|c|c|c|c|c|c|c|}
\hline & 1. & 2. & 3. & 4. & 5. & 6. & 7. & 8. & 9. & 10. & \\
\hline 1. TU (Budner Questionary) & & -.060 & $.287^{*}$ & -.052 & .145 & -.116 & -.186 & -.019 & .233 & .159 & \\
\hline 2. ITU (Budner Questionary) & .061 & & $-.294^{*}$ & $.274^{*}$ & -.119 & -.014 & .082 & .089 & -.230 & $-.275^{*}$ & \\
\hline 3. Risk-readiness (LFR) & $.453^{*}$ & .052 & & $78^{*}$ & $.316^{*}$ & -.212 & -.221 & -.235 & .237 & $.363^{* *}$ & \\
\hline 4. Rationality (LFR) & $-.401^{*}$ & -.007 & $-.387^{*}$ & & .027 & .022 & $.415^{* *}$ & $.368^{* *}$ & .157 & -.013 & \\
\hline 5. Extraversion (TIPI) & .349 & .096 & .197 & -.206 & & .040 & -.113 & -.139 & .227 & .075 & పั \\
\hline 6. Agreeableness (TIPI) & .194 & .108 & .138 & -.079 & -.089 & & .044 & .210 & -.009 & -.185 & ๑ \\
\hline 7. Conscientiousness (TIPI) & -.250 & -.010 & .034 & $.396^{*}$ & -.193 & .160 & & .136 & .215 & .127 & \\
\hline 8. Emotional stability (TIPI) & -.126 & -.093 & $-.329^{*}$ & .187 & -.121 & .043 & .151 & & .027 & .127 & \\
\hline 9. Openness (TIPI) & .176 & -.241 & .008 & .214 & .197 & -.042 & .114 & .003 & & .163 & \\
\hline 10. Self-esteem of riskiness & .045 & -.086 & $.443^{* *}$ & $-.423^{* *}$ & .174 & -.252 & -.261 & $-.352^{*}$ & -.082 & & \\
\hline
\end{tabular}

Note. ${ }^{*} p<.05,{ }^{* *} p<.01$. Doctors are above the diagonal, realtors are under the diagonal. Avrg-average. 


\section{Appendix 5: Cognitive Risk Representations Questionnaire (CRR)}

You are given a list of risks that may occur in your activity. Please read each question carefully and evaluate each risk as a percentage by putting the number in the appropriate box.

- How risky does this situation seem to you?
1. Get a penalty $\%$
2. Misjudge the situation $\%$
7. Lose your self-esteem $\%$
8. Overestimate yourself $\%$
13. Spend little time with relatives $\%$
14. Spoil your reputation $\%$
5. Become a victim of aggression $\%$
6. Waste time $\%$
11. Make a procedural mistake $\%$
12. Be sued
10. Equipment failure $\%$ $\%$
16. Quarrel with colleagues $\%$
17. Difficult weather conditions $\%$

3. Spoil relations with superiors
9. Psychological overload $\%$

15. Break your health 